\title{
The mutagenic effect of tobacco smoke on male fertility
}

\author{
Temidayo S. Omolaoye ${ }^{1,2}$ (D) $\cdot$ Omar El Shahawy ${ }^{3}$ (D) $\cdot$ Bongekile T. Skosana $^{2} \cdot$ Thomas Boillat $^{1}$ (D) Tom Loney $^{1}$ (D) \\ Stefan S du Plessis ${ }^{1,2}$ (B)
}

Received: 29 May 2021 / Accepted: 30 August 2021 / Published online: 18 September 2021

(C) The Author(s) 2021

\begin{abstract}
Despite the association between tobacco use and the harmful effects on general health as well as male fertility parameters, smoking remains globally prevalent. The main content of tobacco smoke is nicotine and its metabolite cotinine. These compounds can pass the blood-testis barrier, which subsequently causes harm of diverse degree to the germ cells. Although controversial, smoking has been shown to cause not only a decrease in sperm motility, sperm concentration, and an increase in abnormal sperm morphology, but also genetic and epigenetic aberrations in spermatozoa. Both animal and human studies have highlighted the occurrence of sperm DNA-strand breaks (fragmentation), genome instability, genetic mutations, and the presence of aneuploids in the germline of animals and men exposed to tobacco smoke. The question to be asked at this point is, if smoking has the potential to cause all these genetic aberrations, what is the extent of damage? Hence, this review aimed to provide evidence that smoking has a mutagenic effect on sperm and how this subsequently affects male fertility. Additionally, the role of tobacco smoke as an aneugen will be explored. We furthermore aim to incorporate the epidemiological aspects of the aforementioned and provide a holistic approach to the topic.
\end{abstract}

Keywords Tobacco smoke $\cdot$ Genetic aberrations $\cdot$ Mutagen $\cdot$ Aneugens $\cdot$ Spermatozoa $\cdot$ Male infertility

\section{Introduction}

Globally, the prevalence of tobacco smoking remains high, with an estimated $19 \%$ of the adult population using tobacco products: $33 \%$ among males and $6 \%$ among females (World Health Organization 2019). These estimates are concerning as tobacco use has consistently been associated with numerous chronic diseases and adverse health outcomes, including possible mutagenic effects (World Health Organization 2020). There is a strong body of evidence suggesting a causal association between tobacco use and both cardiovascular- and

Responsible Editor: Lotfi Aleya

Stefan S du Plessis

Stefan.duplessis@mbru.ac.ae

1 College of Medicine, Mohammed Bin Rashid University of Medicine and Health Sciences, Dubai, United Arab Emirates

2 Division of Medical Physiology, Faculty of Medicine and Health Sciences, Stellenbosch University, Tygerberg, South Africa

3 Department of Population Health, New York University Grossman School of Medicine, New York City, NY, USA cancer-related morbidity and mortality. A recent metaanalysis of 141 cohort studies reported that even low tobacco use (one cigarette per day) increased the risk of developing coronary heart disease by between 48 and $74 \%$ and smokers consuming 20 cigarettes per day were twice as likely to develop coronary heart disease (Hackshaw et al. 2018). Similarly, recent meta-analyses have reported a doseresponse relationship between cigarette consumption and various types of cancer including bladder (Cumberbatch et al. 2016), kidney (Santucci et al. 2019), lung (O'Keeffe et al. 2018), ovarian (Santucci et al. 2019), pancreatic (Lugo et al. 2018), and prostate cancer (Islami et al. 2014). Cardiovascular and neoplastic health risks persist across other types of tobacco use including waterpipes (Montazeri et al. 2017) and smokeless tobacco (Sinha et al. 2018), and also exposure to environmental tobacco smoke (Zhang et al. 2020).

Not only has the association between tobacco smoke and cardiovascular- and cancer-related morbidity been shown; findings have also highlighted the adverse impact of tobacco smoke on male fertility (Sharma et al. 2016; Pizzol et al. 2021). Tobacco smoke contains several toxic and mutagenic substances, including nicotine, a psychoactive substance. Nicotine and its metabolite, cotinine, can cross the blood- 
testis barrier, which subsequently causes harm of diverse degree to the germ cells. Tobacco smoke has been reported to cause not only a decrease in sperm motility (although controversial), sperm concentration, and an increase in abnormal sperm morphology, but also abnormal protein expression, and both genetic and epigenetic aberrations in spermatozoa (Pereira et al. 2014). Studies have further provided evidence that tobacco smoke can serve as a mutagen and an aneugen of germ cell/spermatozoa (Marchetti et al. 2011; Linschooten et al. 2013; Pereira et al. 2014).

Although there is conflicting evidence on the mechanism of action of tobacco smoke on male fertility (du Plessis et al. 2014), the reported adverse effects ranging from the germlines to mature spermatozoa and overall male fertility cannot be overlooked. As such, the primary aim of this review is to provide an update on the evidence from animal and human research on the possible biological pathways through which tobacco use and exposure might cause adverse changes in sperm parameters leading to male infertility. Additionally, this review will also provide evidence that smoking has a mutagenic and an aneugenic effect on sperm and how this subsequently affects male fertility.

\section{Search methods}

A literature search was performed of all relevant information related to tobacco smoking, its effect on human sperm parameters, and its role as a mutagen. Electronic databases including Google Scholar, PubMed, and the National Centre for Biotechnology Information (NCBI) were made use of to carry out these searches. Keywords such as "tobacco/cigarette smoking," "sperm parameters," "sperm DNA fragmentation," "mutagen," and "aneugen" were utilized to perform the searches. Literature was limited to articles written in English. Additionally, literature results that tested the effect of tobacco smoke on animals were included in this document for mechanisms of action to be explained. Represented in Table 1 is a summary of the number of scientific articles published on these topics as distributed over a period of 5 years as retrieved from PubMed. It is worth noting that cigarette and tobacco smoke are used interchangeably in this manuscript.

\section{Types of tobacco use and sources of tobacco smoking}

Tobacco can be consumed in a wide variety of smoked and smokeless products. Tobacco smoking is the combustion of tobacco leaves and inhalation of the smoke. The most common methods of smoking tobacco include manufactured and hand-rolled cigarettes and cigars (worldwide, Europe, and Asia), waterpipes (Middle East, North Africa, and parts of Asia), pipes (worldwide), and more recently electronic nicotine delivery systems (North America and Europe) (Asma et al. 2015). Smokeless tobacco is consumed through the mouth or nose, without combustion or burning. The most common consumption of smokeless tobacco includes chewing tobacco (Africa, Asia, and North America), and both moist snuff (Asia, Middle East, North America, and South Africa) and dry snuff (Brazil, Europe, South and Central Asia, Nigeria, South Africa, and North America) (Asma et al. 2015). Primary exposure refers to inhalation of tobacco smoke or consumption of smokeless tobacco products (e.g., chewing tobacco, snuff) by the individual user. Secondary tobacco smoke exposure (also called environmental tobacco smoke) is inhalation of someone else's, e.g., cigarette, cigar, or pipe smoke generated from combustion of tobacco products.

\section{Content of tobacco smoke}

Firstly, tobacco use is of interest to male reproductive researchers as it contains over 7000 compounds, of which approximately 70 have been identified as carcinogenic (Hecht 2003; IARC 2012). Different toxicants present in tobacco smoke is reviewed in detail by Shihadeh et al. (Shihadeh et al. 2015; Nardone et al. 2019). Combustible tobacco products cause the emission, and hence exposure to gases, vaporized liquids, and particles through the processes of hydrogenation, pyrolysis, oxidation, decarboxylation, and dehydration (du Plessis et al. 2014). There are two phases of cigarette smoke with nicotine and tar released in the particulate phase, and carbon monoxide emitted in the gaseous phase (Hammond et al. 2006). A wide range of carcinogens and mutagens, including radioactive polonium, benzopyrene, dimethylbenzanthracene, naphthalene methylnaphthalene, polycystic aromatic hydrocarbons, and heavy metals such as cadmium, have been found in cigarette smoke (Hosseinzadeh Colagar et al. 2007; Richthoff et al. 2008; Dai et al. 2015). Some of these chemicals have been proven to be extremely detrimental to male fertility.

\section{Prevalence of male infertility}

Infertility is defined as the inability of a couple to conceive after 1 year of unprotected intercourse (Lyu et al. 2017). Globally, $\sim 15 \%$ of couples of reproductive age are affected by infertility and the distribution of infertility due to male factor ranges from 20 to $70 \%$ with the prevalence of male infertility in North America, Australia, and Central and Eastern Europe varied from 4.5 to $6 \%, 9 \%$, and 8 to $12 \%$, respectively (Agarwal et al. 2015). Data from the past 80 years suggests a temporal decline in semen quality. An earlier review $(N=14,947 ; 61$ papers $1938-1991)$ reported that mean seminal volume significantly decreased from 3.40 to $2.75 \mathrm{ml}$ between 1940 and 1990 with an estimated decline of $-0.0130 \mathrm{ml} /$ year (Carlsen et al. 1992). Similarly, a significant decrease in mean sperm concentration from $113 \times 10^{6}$ to 66 
Table 1 Summary of publication distribution related to tobacco smoking

\begin{tabular}{|c|c|c|c|c|c|c|c|c|c|}
\hline \multirow[b]{3}{*}{ Keywords } & \multicolumn{9}{|c|}{ PubMed articles } \\
\hline & \multicolumn{3}{|c|}{ Publications from 1807 to 2021} & \multicolumn{6}{|c|}{ Publications during the last 5 years } \\
\hline & $\begin{array}{l}\text { Review } \\
\text { articles }\end{array}$ & $\begin{array}{l}\text { Systematic } \\
\text { reviews }\end{array}$ & $\begin{array}{l}\text { All } \\
\text { publications }\end{array}$ & 2016 & 2017 & 2018 & 2019 & 2020 & $\begin{array}{l}5 \text { years } \\
\text { total }\end{array}$ \\
\hline "Tobacco" & 12,810 & 1672 & 140,918 & 7587 & 7372 & 8119 & 8380 & 9038 & 40,496 \\
\hline "Tobacco" AND "male infertility" & 40 & 7 & 115 & 3 & 7 & 12 & 9 & 8 & 39 \\
\hline "Tobacco" AND “sperm” & 39 & 8 & 255 & 11 & 10 & 17 & 16 & 19 & 73 \\
\hline "Tobacco" AND “sperm DNA fragmentation" & 2 & 0 & 16 & 1 & 2 & 2 & 0 & 1 & 6 \\
\hline "Tobacco" AND “sperm” AND “mutagenic" & 3 & 0 & 9 & 0 & 0 & 0 & 0 & 0 & 0 \\
\hline $\begin{array}{l}\text { "Tobacco" AND "sperm" AND "mutagen, } \\
\text { mutagenic" }\end{array}$ & 4 & 0 & 15 & 1 & 1 & 1 & 0 & 0 & 3 \\
\hline "Tobacco" AND "sperm, aneugen" & 43 & 8 & 285 & 11 & 12 & 19 & 16 & 21 & 79 \\
\hline
\end{tabular}

$\times 10^{6} / \mathrm{ml}$ was observed between 1940 and 1990 with an estimated decrease of $-0.934 \times 10^{6} / \mathrm{ml}$ per year (Carlsen et al. 1992). Swan and colleagues (2000) expanded the work of Carlsen et al. (1992) by including an additional 47 studies and re-analyzed the data from 1934 to 1996 and reported significant declines in sperm concentration in the USA (approximately $1.5 \% /$ year) and Europe/Australia (approximately $3 \% /$ year) that were markedly greater than the average decline reported by Carlsen et al. (1992) (approximately 1\%/year). Although there were limited data available, the review did not find a decline in sperm concentration in non-Western countries. The etiology remains unknown (termed idiopathic infertility) in approximately half of infertile males with the clinical sperm profile showing oligospermia, asthenospermia, teratozoospermia, or other sperm abnormalities (Lyu et al. 2017). A recent comprehensive meta-analysis reported that sperm counts, whether measured as sperm count or total sperm count, declined significantly among men from North America, Europe, and Australia during 1973-2011, with a $50-60 \%$ decline among men unselected by fertility, with no evidence of a "leveling off" in recent years. These findings strongly suggest a significant decline in male reproductive health, which has serious implications beyond fertility concerns (Levine et al. 2017).

\section{Epidemiology of tobacco use and male infertility}

Numerous risk factors have been proposed for male infertility including erectile dysfunction, varicocele, congenital dysplasia, endocrine disorders, immune factors, sexually transmitted infections, and exposure to chemicals and radiation (Krausz, 2011). There is an emerging body of evidence to suggest the possible role of tobacco use in the etiology of male infertility due to changes in sperm parameters. A cross-sectional study of 1165 males aged 16-29 years from Estonia $(N=573)$,
Latvia $(N=278)$, and Lithuania $(N=314)$ was conducted in 2003-2004 to investigate the sperm quality parameters in Baltic men (Erenpreiss et al. 2017). The median sperm concentration was $63 \times 10^{6} / \mathrm{ml}$ and low semen quality was detected in 11-15\% of the men. Smoking had an adverse impact on both sperm concentration and total sperm counts with smokers having significantly lower sperm concentrations (median 60 versus $\left.66 \times 10^{6} / \mathrm{ml}, P=0.02\right)$ and lower total sperm counts, $\left(177\right.$ versus $\left.226 \times 10^{6}, P<0.001\right)$ than non-smokers (Erenpreiss et al. 2017). Cross-sectional data cannot infer the direction of the relationship; therefore, data from robust longitudinal cohort designs provide stronger evidence on the temporality and possible causal association between tobacco use and male infertility. The Nanjing Medical University Longitudinal Investigation of Fertility and the Environment (NMU-LIFE) study investigated the effects of cigarette smoking on sperm quality among 1631 fertile men in China. The study reported a significant decrease in semen volume and total sperm count, and a significant increase in total motility and progressive motility in ever smokers of pack-years $\geq 10$ compared with never smokers (Tang et al. 2019). Interestingly, the study reported an inverse dose-dependent relation between smoking pack-years and semen volume and total sperm count, and a positive dose-dependent relation between smoking pack-years and both total motility and progressive motility (Tang et al. 2019). The observed inverse dose-response association between cigarette smoking and sperm quality suggests a causal association. Moreover, the negative impact seems to be reversible as the detrimental effects of smoking on semen quality were not observed in men classified as former smokers (i.e., quit smoking for at least 6 months and had smoked for at least 1 year) (Tang et al. 2019). A recent systematic review and meta-analysis of 16 studies ( $N=10,823$ infertile male participants; 5257 smokers and 5566 non-smokers) showed that smokers were $26 \%$ more 
likely to have oligozoospermia than non-smokers (relative risk: 1.29 ; 95\% CI: $1.05-1.59 ; P=0.02$ ) (Bundhun et al. 2019). Compared to non-smokers, morphological defects of spermatozoa (mean difference (MD): 2.44; 95\% CI: 0.99 3.89; $P=0.001)$ was also significantly higher in smokers with significant head (MD: $1.76 ; 95 \%$ CI: $0.32-3.20 ; P=$ 0.02 ), neck (MD: $1.97 ; 95 \%$ CI: $0.75-3.18 ; P=0.002$ ), and tail (MD: 1.29 ; 95\% CI: $0.35-2.22 ; P=0.007$ ) defects (Bundhun et al. 2019). Smoking did not affect the $\mathrm{pH}$ (MD: 0.04 ; 95\% CI: $-0.03-0.11 ; P=0.30$ ) or motility (RR: 1.42 ; 95\% CI: $0.97-2.09 ; P=0.07)$ of spermatozoa, or cause any disbalance in reproductive hormones (Bundhun et al. 2019). Another recent review presented data on more than 60 studies reporting the relationship between tobacco use and impaired seminal parameters in both animal and human models (Beal et al. 2017) Moreover, the available evidence in the review provides support for the notion that nicotine and chemical contained in tobacco can permeate the blood-testis barrier and act as a mutagen on human germ cells (Beal et al. 2017).

\section{Smoking and sperm function}

Represented in Fig. 1 are some of the effects of tobacco smoke on male reproductive parameters and its impact on genome integrity. A systematic review and meta-analysis conducted by Bundhun et al. (Bundhun et al. 2019), which analyzed 10,823 infertile males (smokers and non-smokers) with a mean age of 26.5-40.5 years, found smoking to affect both sperm quality and sperm quantity. Smoking was associated with reduced sperm counts and increased morphologically abnormal sperm (head, neck, and tail defects). Motility, however, was a contentious outcome. This meta-analysis found tobacco smoking to have no effect on motility, whereas several other articles observed a negative effect (Lingappa et al. 2015; Asare-Anane et al. 2016; Sharma et al. 2016).
Furthermore, in general, tobacco smoking has been found to reduce semen volume, sperm concentration, and total sperm count (Asare-Anane et al. 2016), although few studies have shown no effect (Trummer et al. 2002). Numerous mechanisms have been postulated regarding how these changes can come about. These are discussed in detail in later paragraphs. The consensus among authors is that cigarette smoking reduces all conventional (basic) sperm parameters, despite parameters such as motility. However, in many cases, progressive motility is reported, and it is found to be reduced (Mostafa et al. 2018; Boeri et al. 2019). As cigarette smoke has numerous compounds and carcinogens, studies have also been performed on the individual constituents to observe their effects on reproduction. Benzo[a]pyrene, a polycyclic aromatic hydrocarbon and powerful carcinogen and mutagen (Kaiserman and Rickert 1992), has been shown in vitro to induce higher percentages of acrosome reaction and hyperactivation with increasing concentrations of benzo[a]pyrene (Mukhopadhyay et al. 2010). Nicotine can cross the bloodtestis barrier and is found in high concentrations within the seminal plasma of tobacco smokers (Pacifici et al. 1993; Abuawwad et al. 2016). Nicotine has been shown by both in vitro and in vivo animal models to affect sperm parameters (Gandini et al. 1997; Cope and Gandini 1998; Oyeyipo et al. 2010, 2014; Ezzatabadipour et al. 2012). Oyeyipo et al. (2014) observed high levels of nicotine to induce premature acrosome reactions in spermatozoa and to reduce sperm motility and viability in vitro. Furthermore, cotinine, the main metabolite of nicotine, reduces sperm concentrations, total sperm count, and sperm motility (Vine et al. 1996). While almost all the human studies pertaining to the effects of smoking and sperm function has primarily considered cigarette smoking, other combustible tobacco products likely have the same impact such as hookah (or waterpipe) and cigars. Moreover, electronic cigarettes, although they are not
Fig. 1 Effects of tobacco smoke on male fertility and its impact on genome integrity. Tobacco smoke has been shown to impair reproductive processes (spermatogenesis), semen or sperm parameters (concentration, semen volume), and sperm function (motility). In addition to tobacco smoke being regarded as an endocrine disruptor, it has been shown to cause increased sperm DNA fragmentation, sperm mutagenesis, and sperm aneuploidy, and can also lead to several genetic mutations, which cumulatively affects male fertility

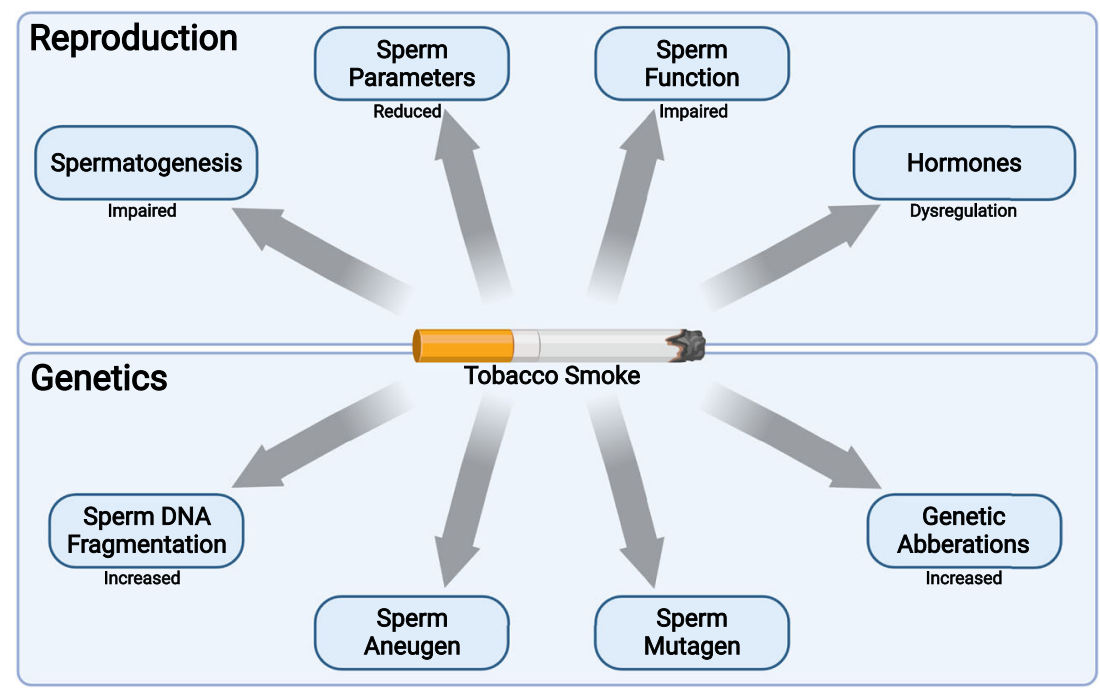


classified as combustible products, can deliver high levels of nicotine similar to that of cigarettes (Farsalinos et al., 2014). There is no reason to expect these products to not impact sperm function and male infertility; however, empirical research is needed to evaluate its level of harm in comparison to cigarette smoking (Corona et al. 2020).

\section{Smoking and sperm production}

Tobacco smoking reduces sperm concentration. This has been postulated to occur via several mechanisms including a reduction of spermatogenesis via impaired hormone and enzyme production, as well as histological damage to reproductive organs. Tobacco smoke has been proposed to be an endocrine disruptor. Blanco-Muñoz et al. (2012) were able to show that smokers have higher luteinizing hormone ( $\mathrm{LH})$, prolactin, and testosterone levels, but no effect on follicle-stimulating hormone (FSH), estradiol, and inhibin B. Other authors have also reported higher testosterone concentrations in smokers versus non-smokers, even after adjusting for age and anthropometric parameters (Field et al. 1994; Bønaa et al. 2003; Svartberg and Jorde 2007). In addition, clinical studies have shown a positive correlation between increased serum nicotine levels and higher levels of prolactin (Mendelson et al. 2003; Xue et al. 2010). Other studies, however, have not been able to show changes in hormone concentrations (Bundhun et al. 2019). Exposure to cigarette smoke has been observed to reduce the activity of sorbitol dehydrogenase and increase lactate dehydrogenase, both key enzymes in spermatogenesis and sperm maturation (Abdul-Ghani et al. 2014). In cigarette smokeexposed young mice, histological assessment of the testis revealed smaller seminiferous tubules, atrophy, and tubular degeneration, as well as a reduction in the spermatogenic cell layer (La Maestra et al. 2015). These changes can negatively affect sperm production.

\section{Smoking and sperm DNA fragmentation}

Tobacco smoking has been investigated by numerous studies to assess its effects on sperm DNA fragmentation. In a prospective randomized study analyzing 108 couples with unexplained infertility undergoing fertility treatment, 26 of the male counterparts were found to be smokers (Aboulmaouahib et al. 2018). Sperm DNA fragmentation and chromatin decondensation were analyzed via TUNEL (terminal deoxynucleotidyl transferase dUTP nick end labeling) assay and aniline blue staining respectively; both DNA fragmentation (26\%) and chromatin decondensation $(25 \%)$ were shown to be significantly higher in the smokers compared to the non-smokers (controls). Using the comet assay, La Maestro et al. (2015) observed both single- and doublestranded breaks to be significantly higher in mice exposed to cigarette smoke from birth to early childhood compared to controls.

\section{Mechanisms through which tobacco smoke affects male fertility}

Most studies have reported several reproductive abnormalities such as impaired spermatogenesis, reduced semen quality, and altered sperm function in men that smoke tobacco (Martini et al. 2004; La Maestra et al. 2015). These outcomes are in part underlined by the increased formation of reactive oxygen species (ROS) leading to the development of oxidative stress (OS), DNA damage, and germ cell apoptosis. Although ROS is required for physiological processes (Haque et al. 2014), the abnormal accumulation thereof can lead to DNA strand breaks, peroxidation of unsaturated lipids, disruption of mitochondrial function, and oxidative damage to DNA (Fullston et al. 2017; Roychoudhury et al. 2017). Spermatozoa are vulnerable to ROS due to the presence of limited cytoplasmic antioxidants and limited repair mechanisms (Attia et al. 2014). Due to the translational and transcriptional inert nature of DNA, the DNA damage borne in sperm DNA persists (Attia et al. 2014).

Kumar et al. (2015) reported an increase in seminal ROS with a subsequent rise in sperm DNA fragmentation index and elevated 8-hydroxy-2-deoxyguanosine (8-OHdG) levels in the semen samples collected from smoking men. Another study reported a decrease in the activity of sperm glutathione peroxidase $(\mathrm{GPx}-1,4)$ and a reduction in the mRNA expression of glutathione reductase in the spermatozoa of smoking men (Viloria et al. 2010). Several other authors have reported elevated levels of malondialdehyde and protein carbonyls in the semen of smokers and a reduction in the levels of glutathione-S-transferase and glutathione (Haque et al. 2014; Dai et al. 2015).

Many studies have reported that the contents of tobacco smoke, such as nicotine, can penetrate the blood-testis barrier and subsequently affect the process of spermatogenesis, either by affecting the genetic integrity or by altering hormone production (Toppari et al. 1996; Kumar et al. 2015; Aprioku and Ugwu 2016). Hence, environmental factors such as exposure to endocrine disruptors may affect the integrity of the sperm genome, especially the sperm nucleus where the DNA is loosely bound to histones in the nucleohistone compartment (Jeng 2014). Nicotine acts as an oxidizing agent that subsequently affects the sperm plasma membrane.

The sperm plasma membrane is rich in polyunsaturated fatty acids (PUFA) which are highly susceptible to ROS; its invasion thereof leads to lipid peroxidation (Haque et al. 2014; Harlev et al. 2015). Lipid peroxidation occurs in 3 stages: initiation, propagation, and termination. During initiation, free radicals react with fatty acid chains to form the lipid peroxyl radical. Peroxyl radicals in turn react with fatty acids to 
produce free radicals and the reaction is thus propagated. In termination, the two radicals react with each other which lead to lipid break down (Omolaoye and Du Plessis 2018). Hence, an increase in an oxidizing agent consequently results in (i) sperm plasma membrane PUFA breakdown, (ii) development of oxidative stress, (iii) sperm DNA damage, (iv) impaired spermatogenesis, (v) reduced sperm production, (vi) impaired chromatin remodeling, and (vii) a decrease in the levels of nuclear protamination (Aitken et al. 2014). Looking at the effect of smoking on sperm DNA, it can be suggested that tobacco smoke is not only harmful to the active user, but also can affect the paternal genome to accumulate damage even before fertilization (Kumar et al. 2015). A summary of the mechanism through which tobacco smoke affects male fertility is represented in Fig. 2.

\section{Tobacco smoke as a sperm mutagen}

Mutagenesis is a process by which the genetic information of an organism is changed by the production of a mutation. Mutation is the change in the structure of a gene as a result of exposure to mutagens. A mutagen, on the other hand, is any physical or chemical compound that can cause mutation. Although paternal age has always been emphasized as a major or significant contributor to increased male-related infertility and male-mediated inherited gene mutations (Sun et al. 2012; Kong et al. 2013), in recent years, however, the effect of paternal lifestyle such as tobacco smoking has been shown to contribute to germline mutations, which may not only have an adverse effect on the individual, but also on the offspring (Linschooten et al. 2013). Tobacco smoke has been shown to cause diverse reproductive abnormalities such as abnormal sperm parameters (as described in the section above), sperm DNA breaks, and chromosomal abnormalities, resulting in diverse consequences on the reproductive health of the smoker.

Both human and animal studies have identified tobacco smoke as a sperm mutagen (Yauk et al. 2007; Marchetti et al. 2011; Linschooten et al. 2013). Linschooten et al. in their study identified germline mutations in blood samples of complete mother-father-child traits. It was reported that the presence of these mutations were due to lifestyle. As paternally derived gene mutations increased dose dependently, that is, the offspring of fathers who smoked 6 months before pregnancy had a higher number of mutations compared to nonsmoking fathers (Linschooten et al. 2013). A study that investigated the effect of main stream tobacco smoke on heritable genetic mutations in mice showed that animals exposed to mainstream tobacco smoke for a duration of 6 or 12 weeks exhibited a significant increase in germline mutation in

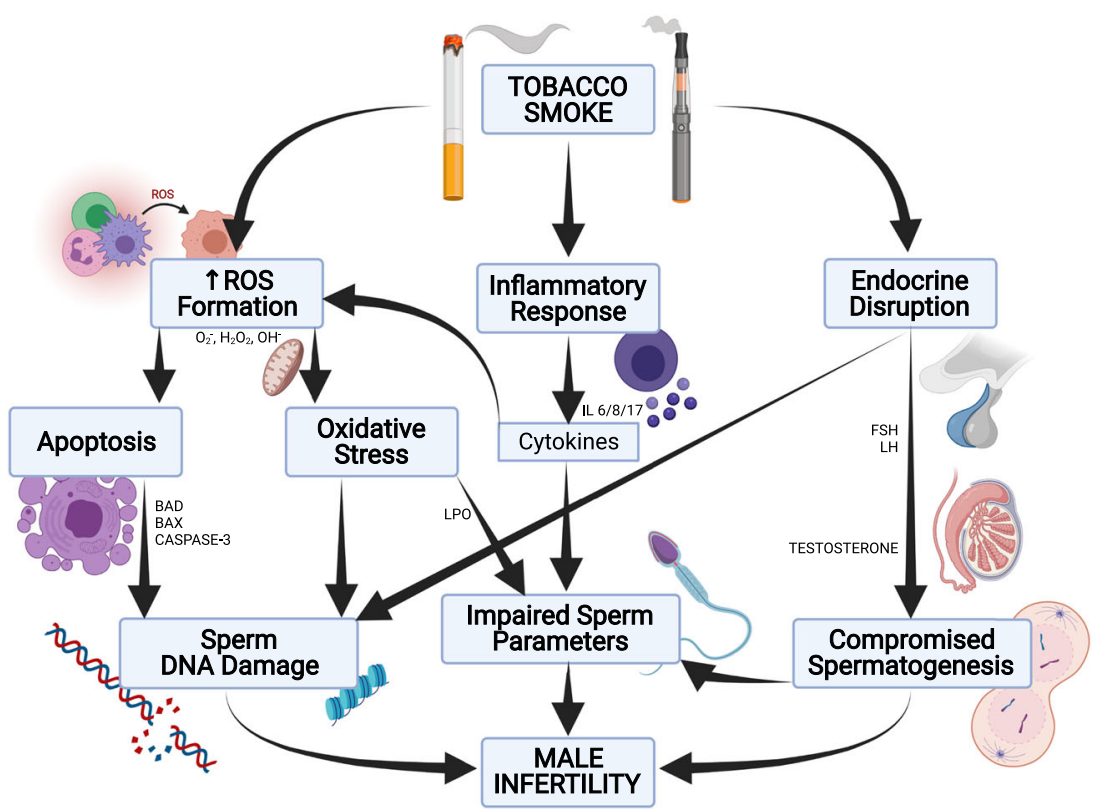

Fig. 2 Mechanisms through which tobacco smoke affects male fertility. Tobacco smoke is known to cause increases in reactive oxygen species (ROS) formation and subsequently result in the development of oxidative stress. The excessive accumulation of ROS causes lipid peroxidation and increased DNA strand breaks, thereby resulting in altered sperm parameters/functions. Increased ROS formation have been shown to result in the development of apoptosis, where the levels of pro-apoptotic cytokines are increased and can further lead to elevated sperm DNA damage and ultimately impaired male fertility. Tobacco smoke substrates can disrupt follicle-stimulating hormone (FSH) and luteinizing hormone (LH) secretion from the anterior pituitary which can impact testosterone synthesis and spermatogenesis. Some of these toxicants can furthermore pass through the blood-testes-barrier, thereby directly affecting testosterone production/secretion and spermatogenesis. Hence, tobacco smoke is a known endocrine disruptor. Additionally, tobacco smoke has been shown to decrease the levels of nuclear protamine/protamination. Also, increased secretion of inflammatory cytokines has been shown in the sera of smokers, which in turn elevate the formation of ROS and consequently result in impaired sperm parameters and ultimately male infertility 
spermatogonial stem cells, and the frequency of mutation was higher in the animals exposed for 12 weeks (Yauk et al. 2007). This suggests that tobacco smoke does not only affect the smoker himself, but the effect can extend to the nonsmoking descendant. Marchetti et al. (2011) reported that the exposure of mice to short-term main stream tobacco smoke ( 2 weeks), and side stream tobacco smoke (second-hand smoke), both induced mutations at an expanded simple tandem repeats locus of mice spermatozoa. This further shows that tobacco smoke is a mutagen of spermatozoa, which could go beyond the smoker.

Findings have also indicated that tobacco smoke alters the microRNA expression in sperm and DNA methylation pattern in other cell types, some of which persisted even after cessation of smoking (Guida et al. 2015). Spermatozoa consist of a complex population of RNA including messenger RNA (mRNA) and micro RNA (miRNA), whose interaction can be used to study the mechanism by which mutagens affects spermatogenesis. A study reported a differential gene expression in the mRNA and miRNA of spermatozoa obtained from smoking men (Metzler-Guillemain et al. 2015). This is supported by another study that reported that tobacco smoke induces specific differences in the spermatozoa miRNA content of smoking men, and that the miRNA appear to be involved in the regulatory pathway that is important for healthy sperm and normal embryo development (Marczylo et al. 2012). Chen et al. also showed that there was alteration in sperm protein expression of mice exposed to tobacco smoke (6 weeks). The proteins affected were related to energy metabolism, reproduction, and structural development molecules (Chen et al. 2015). This shows that smoking can change the presentation and expression of genes that are required for spermatogenesis, which may consequently affect male fertility. Collectively, it can be acknowledged that the recommendation to cease tobacco smoking would not only be advantageous to the immediate primary smoker but would also prevent the development of genetic aberrations in offspring.

\section{Tobacco smoke as sperm aneugen}

An aneugen is any substance that is capable of causing abnormality in the number of chromosomes. Aneugens affect cell division by interacting with the spindle apparatus rather than affecting or interacting with DNA (Faqi et al. 2017). The process of the occurrence of abnormal number of chromosome is called aneuploidy and it has been shown to occur in about $0.3 \%$ of live births and in 5-25\% of mammalian zygotes (Hassold and Hunt 2001). Studies have highlighted that male partners contribute to about $50 \%$ of sex chromosome aneuploidy and that several substances can act as aneugens affecting the spermatogonia (Hassold and Hunt 2001; Robbins et al. 2005). Aneuploidies disrupt gene expression and balance; hence, most aneuploidies result in spontaneous abortion or stillbirth (Hassold and Hunt 2001), but those of the sex chromosomes and some autosomes are compatible to life, and they are associated with developmental disorders. Studies have shown that tobacco smoke can induce aneuploidy in male germ cells (Pereira et al. 2014). A study reported that the spermatozoa of smokers are likely to have an extra chromosome 3 (Pereira et al. 2014), and another study showed that tobacco smoke is associated with an increase in chromosome 1 and chromosome 7 disomies (Härkönen et al. 1999), while several other authors showed that tobacco smoke increases the occurrence of aneuploidies in sperm (Robbins et al. 1997; Shi et al. 2001; Faure et al. 2007). Additionally, the spermatozoa of smokers are likely to have multiple sex chromosomes, such as X-X, Y-Y, and X-Y disomies (Robbins et al. 1997). Hassold et al. suggested that smoking men have about twofold increase in aneuploid sperm and that $0.15 \%$ of live births have autosomal trisomy. They further indicated that male smoking partners contribute to 5-10\% of live birth autosomal trisomies (Hassold et al. 1996). Data have also suggested that approximately $0.02 \%$ of children born to male smokers would carry an abnormal number of autosomal chromosomes (Beal et al. 2017).

\section{Epidemiology of smoking and genetic aberrations}

Earlier sections of this review presented recent evidence showing a strong association between tobacco use and decreased male fertility via a reduction in semen quality; however, the biological mechanism(s) by which tobacco use affects semen quality is not fully understood. Tobacco smoke contains nicotine, carbon monoxide, and heavy metals which are inhaled and transported throughout the body and can pass the blood-testis barrier to reach the seminal plasma (Hamad et al. 2014; Hua et al. 2019). In view that there are continuous cell divisions in the sperm cell differentiation and maturation process (Shukla et al. 2012), it is not surprising that the substances inhaled in tobacco smoke that reach the testes might be implicated in the pathogenesis of reduced sperm quality and male infertility. One proposed mechanism of action is that male infertility, as a result of abnormal spermatozoa, is caused by smoking-induced DNA damage due to activation of the checkpoint kinase 1 (Chk1) which facilitates S and G2 checkpoint arrest (Cui et al. 2016). A recent study in China, on a cohort of 841 smoking men and 287 non-smoking men, showed that abnormal head rates in the heavy smoking group and long-term smoking group were significantly increased compared with the non-smoking group (Cui et al. 2016). Moreover, increased sperm DNA fragmentation rates and decreased Chk1 expression were observed in the smoking group compared to the non-smoking group with an inverse association seen between sperm DNA fragmentation rates and the progressive motility and sperm concentration (Cui et al. 2016). Findings from this study suggest that cigarette 
smoking-induced decrements in semen quality might be caused by DNA damage and apoptosis leading to reduced Chk1 expression and sperm repair, and increased sperm apoptosis (Cui et al. 2016). Similarly, a recent study in Germany analyzed one hundred forty-one sperm samples (43 nonsmokers and 98 heavy smokers) of couples undergoing intracytoplasmic sperm injection and reported significantly lower semen parameters and significantly higher protamine deficiency and sperm DNA fragmentation in heavy smokers (defined as at least one pack a day for 10 years or 2 packs a day for 5 years at least) compared to non-smokers (Amor et al. 2021). In addition, the studied sperm nuclear protein genes (i.e., H2B histone family member $\mathrm{W}$, transition proteins 1 and 2 , and protamine 1 and 2 genes) were differentially expressed and downregulated in the spermatozoa of heavy smokers compared to non-smokers (Amor et al. 2021). These findings suggest that tobacco smoking might reduce normal sperm function by altering the mRNA expression levels of H2BFWT, TNP1, TNP2, PRM1, and PRM2 genes. The available evidence suggests that tobacco smoke may be a human germ cell mutagen that reduces sperm quality through differential expression of important sperm nuclear protein genes.

\section{Innovative ways to curtail smoking}

Tobacco smoke has a wide range of negative health consequences on human health including male fertility which can be reduced or even reversed with smoking cessation. Therefore, innovative approaches to smoking cessation are urgently needed at the population-level. In the last decade, an increasing number of digital solutions have been developed to curtail or help to stop smoking. These drug-free solutions offer new alternatives to the traditional nicotine patch (Fiore et al. 1994). The majority of these solutions leverage the large penetration of mobile devices that equip as many as 3.6 billion of people worldwide (Shoaib et al. 2018). Deployed as mobile applications, the solutions support smokers in the creation of customized plans according to the gender, age, smoking history, current consumption, and goals (Bricker et al. 2017; Chen et al. 2018). These plans are then enacted by different approaches and techniques as shown in Fig. 3. Some solutions are passive and include motivational short text messages, videos describing the benefits of a smoking-free life, or tips to help reduce cigarette consumption. Others involve the smoker in games or engage them in live coaching sessions (Ortis et al. 2020). In order to track cigarette consumption, mobile applications implement two types of loggers. The first type is subjective and requires the smoker to enter the smoking of each cigarette, while the second is objective and rely on smartwatches (Cole et al. 2017; Shoaib et al. 2018) or proprietary wristbands (Lopez-Meyer et al. 2013; Lu et al.
Customized cessation plans

Created from smokers' habits, behaviors and goals

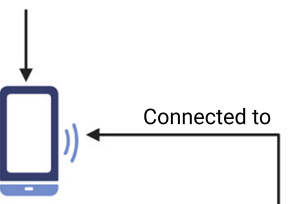

Translate plans into action-driven contents and activities

4 Support

Asynchronous

- Tips

- Videos

- Text messages

- Games

Synchronous:

- Live coaching

Objective measurements of progress

- Smoking activities (e.g., number of cigarettes or puffs per day) by means of smartwatches or proprietary wristbands

- Level of carbon monoxide present

in the body by means of proprietary device

Fig. 3 Innovative ways to curtail smoking

2019) to detect the number of cigarettes and puffs. The Pivot app goes one step further and employs a breath sensor connected to the smoker's mobile device. This allows for objectively assessing the level of carbon monoxide, as marker of smoking, present in the body (Marler et al. 2020). Though some of these mobile applications and devices have been empirically evaluated, no systematic research has compared the efficacy of the different techniques.

\section{Strategies to manage male fertility in active smokers}

The above section has highlighted some innovative ways through which active smokers can gradually curtail smoking and how the cessation thereof can help improve male fertility. The question remains, how about an active smoker who has refused to cease smoking? This section will briefly highlight some strategic ways to manage/improve male fertility in active tobacco smokers.

Some of the ways in which fertility can be improved in men who are not willing to quit smoking include (i) antioxidant therapy, (ii) nicotine replacement therapy, and (iii) assisted reproduction.

\section{Antioxidant therapy}

Antioxidants are substances that inhibit oxidation of biologically relevant molecules, either by directly scavenging free radicals or by chelation of redox metals. They can be enzymatic (superoxide dismutase, catalase, and glutathione peroxidase), non-enzymatic (glutathione; n-acetylcysteine; vitamins $\mathrm{E}$, A, and C; coenzyme Q10; carnitines; myo-inositol; lycopene), and antioxidants derived from nutrients (selenium, zinc, and copper), which can protect the body against OS (Zini et al. 2009; Walczak-Jedrzejowska et al. 2013; Barati et al. 2020). Studies, where antioxidant supplements were 
administered in idiopathic patients, reported an improvement in semen parameters (Ciftci et al. 2009; Ener et al. 2016; Smits et al. 2019). The supplements included vitamin $\mathrm{E}$ (Ener et al. 2016), selenium (Scott et al. 1998), N-acetylcysteine (Ciftci et al. 2009), and carnitine (Smits et al. 2019). In contrast to these findings, Steiner et al. (2020) reported that after administration of an antioxidant formulation containing $500 \mathrm{mg}$ of vitamin C, $400 \mathrm{mg}$ of vitamin E, $0.20 \mathrm{mg}$ of selenium, $1000 \mathrm{mg}$ of L-carnitine, $20 \mathrm{mg}$ of zinc, $1000 \mu \mathrm{g}$ of folic acid, and $10 \mathrm{mg}$ of lycopene daily, to either treatment or placebo group, semen parameters or DNA integrity among men with male factor infertility did not improve (Steiner et al. 2020). The absence of effect may be due to the lack in large sample size or duration or due to other unknown causes. Despite the controversy, antioxidant therapy/supplements are currently being promoted to treat male factor infertility, as there are biological evidence that supports the hypothesis that antioxidants would improve male fertility.

\section{Nicotine replacement therapy}

The aim of nicotine replacement therapy is to reduce motivation to consume tobacco and to also decrease the physiological and psychomotor withdrawal symptoms through the delivery of nicotine (Stead et al. 2008). This line of treatment has become well accepted as it is mostly recommended for people seeking pharmacological help to reduce or stop smoking (Le Foll et al. 2005). Although nicotine is the key active ingredient of tobacco smoke, studies have attributed the toxicity of tobacco smoking to tobacco's other components, which are also responsible for widespread mortality and morbidity (Balfour 2004; Benowitz 2009). The most common and widely studied and implemented pharmacotherapy for managing nicotine dependence and withdrawal is the therapeutic use of nicotinecontaining medications (Wadgave and Nagesh 2016). Nicotine replacement therapy products can be in the form of (i) gum, (ii) transdermal patch, (iii) nasal spray, (iv) oral inhaler, and (v) tablet.

The removal of all other tobacco components (released during combustion) will reduce the negative impact of tobacco smoke on male fertility, and the scrutinized monitoring of the nicotine level released through these nicotine replacement products will further lessen the adverse effect thereof.

\section{Assisted reproduction}

Male factor infertility can be managed through Assisted Reproductive Technologies. Depending on the severity, specifically taking into account sperm concentration and motility, intrauterine insemination IUI, in vitro fertilization (IVF), or intracytoplasmic sperm injection (ICSI) can be recommended (Bhattacharya et al. 2001; Palermo et al. 2015).

\section{Conclusion and recommendation}

Although the associated health risk of tobacco smoke is well documented, the global prevalence of smokers remains high. Tobacco smoke contains several toxic and mutagenic substances, some of which can cross the blood-testis barrier, and subsequently result in altered male reproductive parameters. Not only is the content of tobacco smoke implicated in the pathogenesis of male infertility; its contents have been shown to be a mutagen and an aneugen of spermatozoa, where the genetic mutations are not only seen in the spermatogonial stem cells of the smoker but also seen in the offspring. Findings have also shown that tobacco smoke can alter the microRNA expression in sperm, causing DNA methylation patterns in other cell types, some of which persisted even after cessation of smoking. This means that the adverse effect of tobacco smoking goes beyond the immediate smoker. Hence, it is recommended that male smokers should stop smoking tobacco well in advance of planning to have children and we have highlighted some novel smoking cessation solutions in the current review. Future studies should include data on smokeless tobacco and alternative ways in which nicotine is delivered into the system such as electronic cigarettes. The association between mutagenesis due to smoking and potential impacts on epigenetics should also be investigated further.

Availability of data and materials Not applicable.

Author contribution T. S. O. = conceptualized, drafted, reviewed, edited.

T. L. = drafted, reviewed, edited.

B. T. S. = drafted, reviewed, edited.

E. O. = drafted, reviewed, edited.

T. B. = drafted, reviewed, edited.

S. S. D. P. = conceptualized, reviewed, edited.

Funding This study was partially supported by the Al Jalila Foundation.

\section{Declarations}

Ethics approval and consent to participate Not applicable

Consent for publication Not applicable.

Competing interests The authors declare no competing interests.

Open Access This article is licensed under a Creative Commons Attribution 4.0 International License, which permits use, sharing, adaptation, distribution and reproduction in any medium or format, as long as you give appropriate credit to the original author(s) and the source, provide a link to the Creative Commons licence, and indicate if changes were made. The images or other third party material in this article are included in the article's Creative Commons licence, unless indicated otherwise in a credit line to the material. If material is not included in the article's Creative Commons licence and your intended use is not permitted by statutory regulation or exceeds the permitted use, you will need to obtain 
permission directly from the copyright holder. To view a copy of this licence, visit http://creativecommons.org/licenses/by/4.0/.

\section{References}

Abdul-Ghani R, Qazzaz M, Dabdoub N et al (2014) Studies on cigarette smoke induced oxidative DNA damage and reduced spermatogenesis in rats. J Environ Biol 35:943-947

Aboulmaouahib S, Madkour A, Kaarouch I et al (2018) Impact of alcohol and cigarette smoking consumption in male fertility potential: looks at lipid peroxidation, enzymatic antioxidant activities and sperm DNA damage. Andrologia 50:e12926. https://doi.org/10.1111/and.12926

Abu-awwad A, Arafat T, Schmitz OJ (2016) Simultaneous determination of nicotine, cotinine, and nicotine $\mathrm{N}$-oxide in human plasma, semen, and sperm by LC-Orbitrap MS. Anal Bioanal Chem 408:64736481. https://doi.org/10.1007/s00216-016-9766-7

Agarwal A, Ahmad G, Sharma R (2015) Reference values of reactive oxygen species in seminal ejaculates using chemiluminescence assay. J Assist Reprod Genet 32:1721-1729. https://doi.org/10.1007/ s10815-015-0584-1

Aitken RJ, Smith TB, Jobling MS et al (2014) Oxidative stress and male reproductive health. Asian J Androl 16

Amor H, Zeyad A, Hammadeh ME (2021) Tobacco smoking and its impact on the expression level of sperm nuclear protein genes: H2BFWT, TNP1, TNP2, PRM1 and PRM2. Andrologia 53. https://doi.org/10.1111/and.13964

Aprioku JS, Ugwu TC (2016) Tobacco smoke exposure induces irreversible alteration of testicular function in prepubertal rats. J Basic Clin Physiol Pharmacol 27:577-584. https://doi.org/10.1515/jbcpp2015-0153

Asare-Anane H, Bannison SB, Ofori EK et al (2016) Tobacco smoking is associated with decreased semen quality. Reprod Health 13:90. https://doi.org/10.1186/s12978-016-0207-z

Asma S, Mackay J, Song S et al (2015) The GATS Atlas:2015

Attia SM, Ahmad SF, Okash RM, Bakheet SA (2014) Aroclor 1254 induced genotoxicity in male gonads through oxidatively damaged DNA and inhibition of DNA repair gene expression. Mutagenesis 29:. https://doi.org/10.1093/mutage/geu029

Balfour DJK (2004) The neurobiology of tobacco dependence: a preclinical perspective on the role of the dopamine projections to the nucleus. Nicotine Tob. Res. 6

Barati E, Nikzad H, Karimian M (2020) Oxidative stress and male infertility: current knowledge of pathophysiology and role of antioxidant therapy in disease management. Cell Mol Life Sci 77:93-113. https://doi.org/10.1007/s00018-019-03253-8

Beal MA, Yauk CL, Marchetti F (2017) From sperm to offspring: assessing the heritable genetic consequences of paternal smoking and potential public health impacts. Mutat Res - Rev Mutat Res 773:26-50. https://doi.org/10.1016/j.mrrev.2017.04.001

Benowitz NL (2009) Pharmacology of nicotine: addiction, smoking-induced disease, and therapeutics. Annu. Rev. Pharmacol. Toxicol. 49

Bhattacharya S, Hamilton MPR, Shaaban M et al (2001) Conventional invitro fertilisation versus intracytoplasmic sperm injection for the treatment of non-male-factor infertility: a randomised controlled trial. Lancet. https://doi.org/10.1016/S0140-6736(00)05179-5

Blanco-Muñoz J, Lacasaña M, Aguilar-Garduño C (2012) Effect of current tobacco consumption on the male reproductive hormone profile. Sci Total Environ 426:100-105. https://doi.org/10.1016/j. scitotenv.2012.03.071

Boeri L, Capogrosso P, Ventimiglia E et al (2019) Heavy cigarette smoking and alcohol consumption are associated with impaired sperm parameters in primary infertile men. Asian J Androl 21: 478-485. https://doi.org/10.4103/aja.aja_110_18

Bønaa KH, Joakimsen RM, Jorde R (2003) The association of age, lifestyle factors and chronic disease with testosterone in men: the Tromso study. Eur J Endocrinol 149:145-152
Bricker JB, Copeland W, Mull KE, et al (2017) Single-arm trial of the second version of an acceptance $\&$ commitment therapy smartphone application for smoking cessation. Drug Alcohol Depend 170: https://doi.org/10.1016/j.drugalcdep.2016.10.029

Bundhun PK, Janoo G, Bhurtu A et al (2019) Tobacco smoking and semen quality in infertile males: a systematic review and meta-analysis. J Urol 202:446

Carlsen E, Giwercman A, Keiding N, Skakkebaek NE (1992) Evidence for decreasing quality of semen during past 50 years. Br Med J 305: 609-613. https://doi.org/10.1136/bmj.305.6854.609

Chen T, Zhang X, Jiang H, et al (2018) Are you smoking? Automatic alert system helping people keep away from cigarettes. Smart Heal 9-10:. https://doi.org/10.1016/j.smhl.2018.07.008

Chen X, Xu W, Miao M et al (2015) Alteration of sperm protein profile induced by cigarette smoking. Acta Biochim Biophys Sin Shanghai 47:504-515. https://doi.org/10.1093/abbs/gmv045

Ciftci H, Verit A, Savas M et al (2009) Effects of N-acetylcysteine on semen parameters and oxidative/antioxidant status. Urology 74:7376. https://doi.org/10.1016/j.urology.2009.02.034

Cole CA, Anshari D, Lambert V, et al (2017) Detecting smoking events using accelerometer data collected via smartwatch technology: Validation study. JMIR mHealth uHealth 5:. https://doi.org/10. 2196/mhealth.9035

Corona G, Sansone A, Pallotti F, Ferlin A, Pivonello R, Isidori AM, Maggi M, Jannini EA (2020) People smoke for nicotine, but lose sexual and reproductive health for tar: a narrative review on the effect of cigarette smoking on male sexuality and reproduction. J Endocrinol Invest 43(10):1391-1408. https://doi.org/10.1007/ s40618-020-01257-x. Epub 2020 Apr 22. PMID: 32323225.

Cope GF, Gandini L (1998) The in-vitro effects of nicotine and cotinine on sperm motility. Hum Reprod 13:777-778. https://doi.org/10. 1093/humrep/13.3.777

Cui X, Jing X, Wu X et al (2016) Potential effect of smoking on semen quality through DNA damage and the downregulation of Chk1 in sperm. Mol Med Rep 14:753-761. https://doi.org/10.3892/mmr. 2016.5318

Cumberbatch MG, Rota M, Catto JWF, La Vecchia C (2016) The role of tobacco smoke in bladder and kidney carcinogenesis: a comparison of exposures and meta-analysis of incidence and mortality risks. Eur. Urol. 70

Dai JB, Wang ZX, Qiao ZD (2015) The hazardous effects of tobacco smoking on male fertility. Asian J Androl 17:954-960. https://doi. org/10.4103/1008-682X.150847

du Plessis S, Agarwal A, Sabanegh-jr E (2014) Editors (2014) male infertility: a complete guide to lifestyle and environmental factors. Springer, Sci. Media New York

Ener K, Aldemir M, Issik E et al (2016) The impact of vitamin E supplementation on semen parameters and pregnancy rates after varicocelectomy: a randomised controlled study. Andrologia 48: 829-834. https://doi.org/10.1111/and.12521

Erenpreiss J, Punab M, Zilaitiene B et al (2017) Semen quality of young men from the general population in Baltic countries. Hum Reprod 32. https://doi.org/10.1093/humrep/dex062

Ezzatabadipour M, Azizollahi S, Sarvazad A et al (2012) Effects of concurrent chronic administration of alcohol and nicotine on rat sperm parameters. Andrologia 44:330-336. https://doi.org/10.1111/j. 1439-0272.2012.01284.x

Faqi AS, Koch E, Plassmann S (2017) Chapter 2 - critical aspects of integrated nonclinical drug development: concepts, strategies, and potential pitfalls. In: A Comprehensive Guide to Toxicology in Nonclinical Drug Development

Faure AK, Aknin-Seifer I, Frérot G, et al (2007) Predictive factors for an increased risk of sperm aneuploidies in oligo-asthenoteratozoospermic males. Int J Androl 30:. https://doi.org/10.1111/j. 1365-2605.2006.00726.x 
Field AE, Colditz GA, Willett WC, et al (1994) The relation of smoking, age, relative weight, and dietary intake to serum adrenal steroids, sex hormones, and sex hormone-binding globulin in middle-aged men. J Clin Endocrinol $\{\backslash \&\}$ Metab 79:1310-1316. https://doi.org/10. 1210/jcem.79.5.7962322

Fiore MC, Smith SS, Jorenby DE, Baker TB (1994) The effectiveness of the nicotine patch for smoking cessation: a meta-analysis. JAMA J Am Med Assoc 271:. https://doi.org/10.1001/jama.1994. 03510480064036

Fullston T, McPherson NO, Zander-Fox D, Lane M (2017) The most common vices of men can damage fertility and the health of the next generation. J Endocrinol 234:F1-F6. https://doi.org/10.1530/JOE16-0382

Gandini L, Lombardo F, Lenzi A et al (1997) The in-vitro effects of nicotine and cotinine on sperm motility. Hum Reprod 12:727-733. https://doi.org/10.1093/humrep/12.4.727

Guida F, Sandanger TM, Castagné R, et al (2015) Dynamics of smokinginduced genome-wide methylation changes with time since smoking cessation. Hum Mol Genet 24:. https://doi.org/10.1093/hmg/ddu751

Hackshaw A, Morris JK, Boniface S, et al (2018) Low cigarette consumption and risk of coronary heart disease and stroke: meta-analysis of 141 cohort studies in 55 study reports. BMJ 360

Hamad MF, Shelko N, Kartarius S et al (2014) Impact of cigarette smoking on histone (H2B) to protamine ratio in human spermatozoa and its relation to sperm parameters. Andrology 2. https://doi.org/10. 1111/j.2047-2927.2014.00245.x

Hammond D, Fong GT, Cummings KM et al (2006) Cigarette yields and human exposure: a comparison of alternative testing regimens. Cancer Epidemiol Biomark Prev 15. https://doi.org/10.1158/10559965.EPI-06-0047

Haque O, Vitale JA, Agarwal A, Plessis SS du (2014) The effect of smoking on male infertility. Springer Sci 1-12

Härkönen K, Viitanen T, Larsen SB et al (1999) Aneuploidy in sperm and exposure to fungicides and lifestyle factors. Environ Mol Mutagen 34. https://doi.org/10.1002/(SICI)1098-2280(1999)34:1<39::AIDEM6>3.0.CO;2-F

Harlev A, Agarwal A, Gunes SO et al (2015) Smoking and male infertility: an evidence-based review. World J Mens Health 33:143. https://doi.org/10.5534/wjmh.2015.33.3.143

Hassold T, Abruzzo M, Adkins K, et al (1996) Human aneuploidy: incidence, origin and etiology. In: Environmental and Molecular Mutagenesis

Hassold T, Hunt P (2001) To err (meiotically) is human: the genesis of human aneuploidy. Nat. Rev. Genet. 2

Hecht SS (2003) Tobacco carcinogens, their biomarkers and tobaccoinduced cancer. Nat. Rev. Cancer 3

Hosseinzadeh Colagar A, Jorsaraee GA, Tahmasbpour Marzony E (2007) Cigarette smoking and the risk of male infertility. Pakistan J Biol Sci 10. https://doi.org/10.3923/pjbs.2007.3870.3874

Hua R, Wei H, Liu C et al (2019) FBXO47 regulates telomere-inner nuclear envelope integration by stabilizing TRF2 during meiosis. Nucleic Acids Res 47:11755-11770. https://doi.org/10.1093/nar/gkz992

IARC (2012) A Review of Human Carcinogens. E. Personal habits and indoor combustions. IARC Monographs on the Evaluation of Carcinogenic Risks to Humans. IARC Monogr Eval Carcinog Risks to Humans Volume 100:

Islami F, Moreira DM, Boffetta P, Freedland SJ (2014) A systematic review and meta-analysis of tobacco use and prostate cancer mortality and incidence in prospective cohort studies. Eur. Urol. 66

Jeng HA (2014) Exposure to endocrine disrupting chemicals and male reproductive health. Front. Public Heal. 2

Kaiserman MJ, Rickert WS (1992) Carcinogens in tobacco smoke: benzo[a]pyrene from Canadian cigarettes and cigarette tobacco. Am J Public Health 82:1023-1026. https://doi.org/10.2105/AJPH.82.7.1023

Kong A, Frigge ML, Magnusson G, et al (2013) Rate of de novo mutations, father's age, and disease risk. Nature 488:
Kumar SB, Chawla B, Bisht S et al (2015) Tobacco use increases oxidative DNA damage in sperm - possible etilology of childhood cancer. Asian Pacific J Cancer Prev 16:6967-6972. https://doi.org/10.7314/ APJCP.2015.16.16.6967

La Maestra S, De Flora S, Micale RT (2015) Effect of cigarette smoke on DNA damage, oxidative stress, and morphological alterations in mouse testis and spermatozoa. Int J Hyg Environ Health 218:117122. https://doi.org/10.1016/j.ijheh.2014.08.006

Le Foll B, Melihan-Cheinin P, Rostoker G, Lagrue G (2005) Smoking cessation guidelines: evidence-based recommendations of the French Health Products Safety Agency. Eur. Psychiatry 20

Levine H, Jørgensen N, Martino-Andrade A et al (2017) Temporal trends in sperm count: a systematic review and meta-regression analysis. Hum Reprod Update 23:646-659. https://doi.org/10.1093/humupd/dmx022

Lingappa HA, Govindashetty AM, Puttaveerachary AK et al (2015) Evaluation of effect of cigarette smoking on vital seminal parameters which influence fertility. J Clin Diagn Res 9:EC13-EC15. https://doi.org/10.7860/JCDR/2015/13295.6227

Linschooten JO, Verhofstad N, Gutzkow K et al (2013) Paternal lifestyle as a potential source of germline mutations transmitted to offspring. FASEB J 27:2873-2879. https://doi.org/10.1096/fj.13-227694

Lopez-Meyer P, Patil Y, Tiffany T, Sazonov E (2013) Detection of handto-mouth gestures using a RF operated proximity sensor for monitoring cigarette smoking. Open Biomed Eng J 7:. https://doi.org/10. 2174/1874120701307010041

Lu J, Wang J, Zheng X, et al (2019) Detection of smoking events from confounding activities of daily living. In: ACM International Conference Proceeding Series

Lugo A, Peveri G, Bosetti C, et al (2018) Strong excess risk of pancreatic cancer for low frequency and duration of cigarette smoking: a comprehensive review and meta-analysis. Eur. J. Cancer 104

Lyu Z, Feng X, Li N, et al (2017) Human papillomavirus in semen and the risk for male infertility: a systematic review and meta-analysis. BMC Infect Dis 17:. https://doi.org/10.1186/s12879-017-2812-z

Marchetti F, Rowan-Carroll A, Williams A et al (2011) Sidestream tobacco smoke is a male germ cell mutagen. Proc Natl Acad Sci U S A 108:12811-12814. https://doi.org/10.1073/pnas.1106896108

Marczylo EL, Amoako AA, Konje JC et al (2012) Smoking induces differential miRNA expression in human spermatozoa: a potential transgenerational epigenetic concern? Epigenetics 7:432-439. https://doi.org/10.4161/epi.19794

Marler JD, Fujii CA, Wong KS, et al (2020) Assessment of a personal interactive carbon monoxide breath sensor in people who smoke cigarettes: single-arm cohort study. J Med Internet Res 22:. https:// doi.org/10.2196/22811

Martini AC, Molina RI, Estofán D et al (2004) Effects of alcohol and cigarette consumption on human seminal quality. Fertil Steril 82: 374-377. https://doi.org/10.1016/j.fertnstert.2004.03.022

Mendelson JH, Sholar MB, Mutschler NH et al (2003) Effects of intravenous cocaine and cigarette smoking on luteinizing hormone, testosterone, and prolactin in men. J Pharmacol Exp Ther 307:339348. https://doi.org/10.1124/jpet.103.052928

Metzler-Guillemain C, Victorero G, Lepoivre C et al (2015) Sperm mRNAs and microRNAs as candidate markers for the impact of toxicants on human spermatogenesis: an application to tobacco smoking. Syst Biol Reprod Med 61:139-149. https://doi.org/10. 3109/19396368.2015.1022835

Montazeri Z, Nyiraneza C, El-Katerji H, Little J (2017) Waterpipe smoking and cancer: systematic review and meta-analysis. Tob. Control 26

Mostafa RM, Nasrallah YS, Hassan MM et al (2018) The effect of cigarette smoking on human seminal parameters, sperm chromatin structure and condensation. Andrologia 50:e12910. https://doi.org/ 10.1111/and.12910

Mukhopadhyay D, Nandi P, Varghese AC et al (2010) The in vitro effect of benzo[a]pyrene on human sperm hyperactivation and acrosome 
reaction. Fertil Steril 94:595-598. https://doi.org/10.1016/j. fertnstert.2009.02.031

Nardone N, Jain S, Addo N et al (2019) Sources and biomarkers of secondhand tobacco smoke exposure in urban adolescents. Physiol Behav 20: 493-500. https://doi.org/10.1016/j.acap.2019.12.006.Sources

O'Keeffe LM, Taylor G, Huxley RR et al (2018) Smoking as a risk factor for lung cancer in women and men: a systematic review and metaanalysis. BMJ Open 8

Omolaoye TS, Du Plessis SS (2018) Diabetes mellitus and male infertility. Asian Pacific J Reprod 7:6-14. https://doi.org/10.4103/23050500.220978

Organization WHO (2020) Tobacco. https://www.who.int/news-room/ fact-sheets/detail/tobacco. Accessed 15 May 2021

Ortis A, Caponnetto P, Polosa R, et al (2020) A report on smoking detection and quitting technologies. Int. J. Environ. Res. Public Health 17

Oyeyipo IP, Maartens PJ, du Plessis SS (2014) In vitro effects of nicotine on human spermatozoa. Andrologia 46:887-892. https://doi.org/10. 1111/and.12169

Oyeyipo IP, Raji Y, Emikpe BO, Bolarinwa AF (2010) Effects of oral administration of nicotine on organ weight, serum testosterone level and testicular histology in adult male rats. Niger J Physiol Sci 25:81-86

Pacifici R, Altieri I, Gandini L et al (1993) Nicotine, cotinine, and trans-3hydroxycotine levels in seminal plasma of smokers. Ther Drug Monit 15:358-363. https://doi.org/10.1097/00007691-199310000-00002

Palermo GD, Neri QV, Rosenwaks Z (2015) To ICSI or not to ICSI. Semin Reprod Med. https://oi.org/10.1055/s-0035-1546825

Pereira CS, Juchniuk De Vozzi MS, Dos Santos SA, et al (2014) Smoking-induced chromosomal segregation anomalies identified by FISH analysis of sperm. Mol Cytogenet 7:. https://doi.org/10. 1186/s13039-014-0058-7

Pizzol D, Foresta C, Garolla A et al (2021) Pollutants and sperm quality: a systematic review and meta-analysis. Environ Sci Pollut Res 28: 4095-4103. https://doi.org/10.1007/s11356-020-11589-z

Richthoff J, Elzanaty S, Rylander L et al (2008) Association between tobacco exposure and reproductive parameters in adolescent males. Int J Androl 31. https://doi.org/10.1111/j.1365-2605.2007.00752.x

Robbins WA, Elashoff DA, Xun L, et al (2005) Effect of lifestyle exposures on sperm aneuploidy. Cytogenet. Genome Res. 111. https://doi.org/10. 1002/(SICI)1098-2280(1997)30:2<175::AID-EM10>3.0.CO;2-A

Robbins WA, Vine MF, Young Truong K, Everson RB (1997) Use of fluorescence in situ hybridization (FISH) to assess effects of smoking, caffeine, and alcohol on aneuploidy load in sperm of healthy men. Environ Mol Mutagen 30.

Roychoudhury S, Agarwal A, Virk G, Cho CL (2017) Potential role of green tea catechins in the management of oxidative stress-associated infertility. Reprod BioMed Online 34:487-498. https://doi.org/10. 1016/j.rbmo.2017.02.006

Santucci C, Bosetti C, Peveri G, et al (2019) Dose-risk relationships between cigarette smoking and ovarian cancer histotypes: a comprehensive meta-analysis. Cancer Causes Control 30

Scott R, Macpherson A, Yatest RWS et al (1998) The effect of oral selenium supplementation on human sperm motility. Br J Urol 82: 76-80. https://doi.org/10.1046/j.1464-410X.1998.00683.x

Sharma R, Harlev A, Agarwal A, Esteves SC (2016) Cigarette smoking and semen quality: a new meta-analysis examining the effect of the 2010 World Health Organization Laboratory methods for the examination of human semen. Eur Urol 70:635-645. https://doi.org/10. 1016/j.eururo.2016.04.010

Shi Q, Ko E, Barclay L et al (2001) Cigarette smoking and aneuploidy in human sperm. Mol Reprod Dev 59. https://doi.org/10.1002/mrd.1048

Shihadeh A, Schubert J, Klaiany J et al (2015) Toxicant content, physical properties and biological activity of waterpipe tobacco smoke and its tobacco-free alternatives. Tob Control 24:i22-i30. https://doi.org/ 10.1136/tobaccocontrol-2014-051907
Shoaib M, Incel OD, Scholten H, Havinga P (2018) Smokesense: online activity recognition framework on smartwatches. In: Lecture Notes of the Institute for Computer Sciences, Social-Informatics and Telecommunications Engineering, LNICST

Shukla KK, Mahdi AA, Singh R (2012) Apoptosis, spermatogenesis and male infertility. Front. Biosci. - Elit. $4 \mathrm{E}$

Sinha DN, Suliankatchi RA, Gupta PC et al (2018) Global burden of allcause and cause-specific mortality due to smokeless tobacco use: systematic review and meta-analysis. Tob Control 27. https://doi. org/10.1136/tobaccocontrol-2016-053302

Smits RM, Mackenzie-Proctor R, Yazdani A, et al (2019) Antioxidants for male subfertility. Cochrane Database Syst. Rev. 2019

Stead LF, Perera R, Bullen C, et al (2008) Nicotine replacement therapy for smoking cessation. Cochrane Database Syst. Rev.

Steiner AZ, Hansen KR, Barnhart KT et al (2020) The effect of antioxidants on male factor infertility: the MOXI randomized clinical trial. Fertil Steril 113:552-560. https://doi.org/10.1016/j.fertnstert.2019.11.008.The

Sun JX, Helgason A, Masson G, et al (2012) A direct characterization of human mutation based on microsatellites. Nat Genet 44:. https://doi. org/10.1038/ng.2398

Svartberg J, Jorde R (2007) Endogenous testosterone levels and smoking in men. The fifth Tromsøstudy. Int J Androl 30:137-143. https://doi. org/10.1111/j.1365-2605.2006.00720.x

Tang Q, Pan F, Wu X et al (2019) Semen quality and cigarette smoking in a cohort of healthy fertile men. Environ Epidemiol 3. https://doi.org/ 10.1097/ee9.0000000000000055

Toppari J, Larsen JC, Christiansen P, et al (1996) Male reproductive health and environmental xenoestrogens. Environ. Health Perspect. 104

Trummer H, Habermann H, Haas J, Pummer K (2002) The impact of cigarette smoking on human semen parameters and hormones. Hum Reprod 17:1554-1559. https://doi.org/10.1093/humrep/17.6.1554

Viloria T, Meseguer M, Martínez-Conejero JA et al (2010) Cigarette smoking affects specific sperm oxidative defenses but does not cause oxidative DNA damage in infertile men. Fertil Steril 94: 631-637. https://doi.org/10.1016/j.fertnstert.2009.03.024

Vine MF, Tse CKJ, Hu PC, Truong KY (1996) Cigarette smoking and semen quality. Fertil Steril 65:835-842. https://doi.org/10.1016/ S0015-0282(16)58223-5

Wadgave U, Nagesh L (2016) Nicotine replacement therapy: an overview. Int J Heal Sci 10:425-435. https://doi.org/10.12816/0048737

Walczak-Jedrzejowska R, Wolski JK, Slowikowska-Hilczer J (2013) The role of oxidative stress and antioxidants in male fertility. Cent Eur J Urol 66. https://doi.org/10.5173/ceju.2013.01.art19

World Health Organization (2019) WHO Report on the Global Tobacco Epidemic, 2019

World Health Organization (2020) Tobacco. https://www.who.int/newsroom/fact-sheets/detail/tobacco. Accessed 15 May 2021

Xue Y, Morris M, Ni L et al (2010) Venous plasma nicotine correlates of hormonal effects of tobacco smoking. Pharmacol Biochem Behav 95:209-215. https://doi.org/10.1016/j.pbb.2010.01.007

Yauk CL, Berndt ML, Williams A et al (2007) Mainstream tobacco smoke causes paternal germ-line DNA mutation. Cancer Res 67: 5103-5106. https://doi.org/10.1158/0008-5472.CAN-07-0279

Zhang D, Liu Y, Cheng C, et al (2020) Dose-related effect of secondhand smoke on cardiovascular disease in nonsmokers: systematic review and meta-analysis. Int. J. Hyg. Environ. Health 228

Zini A, San Gabriel M, Baazeem A (2009) Antioxidants and sperm DNA damage: a clinical perspective. J. Assist. Reprod. Genet. 26

Publisher's note Springer Nature remains neutral with regard to jurisdictional claims in published maps and institutional affiliations. 